\title{
Pine Needles as Potential Energy Feedstock: Availability in the Central Himalayan State of Uttarakhand, India
}

\author{
L.D. Kala*, P.M.V. Subbarao \\ Mechanical Engineering Department \\ Indian Institute of Technology Delhi, Hauz Khas, New Delhi - 110016 (India) \\ *Corresponding author.Email-ldkala@yahoo.com; \\ Phone - +91-9313899865; Fax - +91-11-26581121 \\ WREC17 Conference track: Biomass and Waste-to-energy
}

\begin{abstract}
The amount of pine needles (pinus roxburgii) potentially available for use as energy feedstock in the Central Himalayan state of Uttarakhand in India has been estimated. It involves estimating the gross annual amount of pine needle yield followed by a comprehensive identification and quantification of the factors that affect the net annual pine needle yield available as energy feedstock. These factors include considerations such as accessibility, alternative uses, forest fires, other losses, etc., that are influenced by aspects ranging from physical constraints to traditional societal traits. Tree canopy cover method has been used for estimating the gross annual pine needle yield. The information on canopy density is obtained from remote sensing data, that forms the basis for forest classification. The annual gross pine needle yield has been estimated at 1.9 million tonnes while the annual net pine needle yield at 1.33 million tonnes. The annual primary energy potential of pine needles available as energy feedstock has also been estimated. For annual net energy potential estimation, thermal and electrical routes are considered. Electrical energy generation from pine needles using thermochemical conversion has been examined and the corresponding potential for electricity generation been estimated. An installed capacity of $789 \mathrm{MW}$ can be supported with pine needles feedstock for supplying electricity in rural areas for five hours a day. For round the clock generation, an installed capacity of $165 \mathrm{MW}$ can be supported by the pine needle energy feedstock.
\end{abstract}

\section{Keywords}

Pine needle gasification, Gross annual yield, Factors affecting availability as energy feed-stock, Primary and net energy delivery potential. 


\section{Introduction}

Uttarakhand in Central Himalayas, a northern hill state of India, is rich in flora and fauna and the source of the major river systems - Ganga and Sharda. This study brings in focus energy situation in the state where demand exceeds supply. The year 2014-15 recorded the peak electricity demand at 1930 MW and the peak energy shortage between 8 and 46 percent [1]. The state has power generation installed capacity of 2361 MW (in 2015) including state allocation of central generating stations [2]. Almost 17 percent of the population of the state do not have access to electricity, though 99 percent of the villages have been electrified [3]. The demand for electricity has steadily grown since formation of the state in year 2000. This is understandable as the new state had reasonable thrust on industrialisation.

The options available for growth of power generation in Uttarakhand exist in conventional as well as in non conventional sectors. Hydro based generation offers major potential in conventional power generation [4]. But the large dams come with their enormous socio-environmental consequences. In non conventional, solar photovoltaic (PV) has good potential as the state receives enough sunshine [4]. Microhydel based power generation again offers enormous opportunites for harnessing. This technology has advantages over large hydro in terms of environmental and socio-economics. There are pockets where wind energy generation offers good scope and thorough site specific life cycle analysis for such locations is needed before deciding in their favour.

Biomass offers good potential as energy feedstock in the state [5]. Biomass can be used for obtaining thermal energy and electrical energy both. Other uses of biomass can be for domestic applications such as cooking. Uttarakhand has relatively cold climate and wider biomass uses can be exercised, such as for house warming.

Forest based biomass is available in plenty in the state owing to its large forest area. Pine needles are forest biomass and have no major usage as energy feedstock so far. Their useful application is highly desirable. Pine needles are known to be prone to fire, causing loss of forests and forest biomass. The fire catching property can be utilised for gasification of pine needles, generating fuel gas that can be used for 
energy generation, electrical power being the most preferred in such circumstances of remotely scattered energy feedstock.

Pine forests are spread across the length and breadth of the state and pine needles as energy feedstock are therefore suited for decentralised power generation. This energy can also be transmitted through grid if the local demand is not adequate. Physical availability of grid in near vicinity is essential for this. Use of pine needle for energy generation is most likely to have positive impact on energy access in the villages of the state.

Gasification of pine needle makes use of thermochemical conversion technology in a gasifier equipment. The producer gas so generated is cleaned for operating an engine coupled to a generator. A downdraft gasifier is best suited for electricity generation [6,7]. Pine needle is compared with some commonly used gasification feedstocks in Table-1. The calorific value of pine needle is comparable to the most common energy feedstock for a gasifier i.e. wood. It is in fact a shade higher. It however, has lower bulk density. This may render it unsuitable for gasifier unless densified as all low density feedstocks such as agricultural wastes and loose biomass should be $[8,9]$. Figure-1 gives a flow chart for pine needle utilisation for electricity generation using a gasifier.

Table-1: Comparision of pine needle as gasification feedstock

\begin{tabular}{|l|c|c|c|}
\hline \multicolumn{1}{|c|}{$\begin{array}{c}\text { Name } \\
\text { feedstock }\end{array}$} & $\begin{array}{c}\text { Calorific } \\
\text { value } \\
\mathbf{( M J} / \mathbf{k g})\end{array}$ & $\begin{array}{c}\text { Bulk } \\
\mathbf{d e n s i t y} \\
\mathbf{( k g / \mathbf { m } ^ { 3 }} \mathbf{)}\end{array}$ & Source \\
\hline Fuelwood & $7.2-14.4$ & $188-277$ & {$[10]$} \\
\hline Pine needle & 19.44 & 94.33 & {$[11]$} \\
\hline Bagasse & 14.6 & 935.6 & {$[12]$} \\
\hline Rice husk & $13.24-16.2$ & $86-114$ & {$[13]$} \\
\hline
\end{tabular}


Electricity generation through pine needles can also be done for captive power by industrial units in the vicinity of pine forests. These units would mosty lie in industrial segment of small and medium enterprises as large industries are not located in hill areas of the state. This would necessitate dealing with logistics for pine needle collection, transportation and storage.

Densification of pine needle biomass yields briquettes (or pellets) that can be fed in a gasifier for conversion into produer gas fuel. The density may now lie above 400 $\mathrm{kg} / \mathrm{m}^{3}$ depending upon the type of densification process and equipment used [14]. The positive results of pine needle gasification after densification is evident from from some efforts in India and Nepal $[15,16]$.

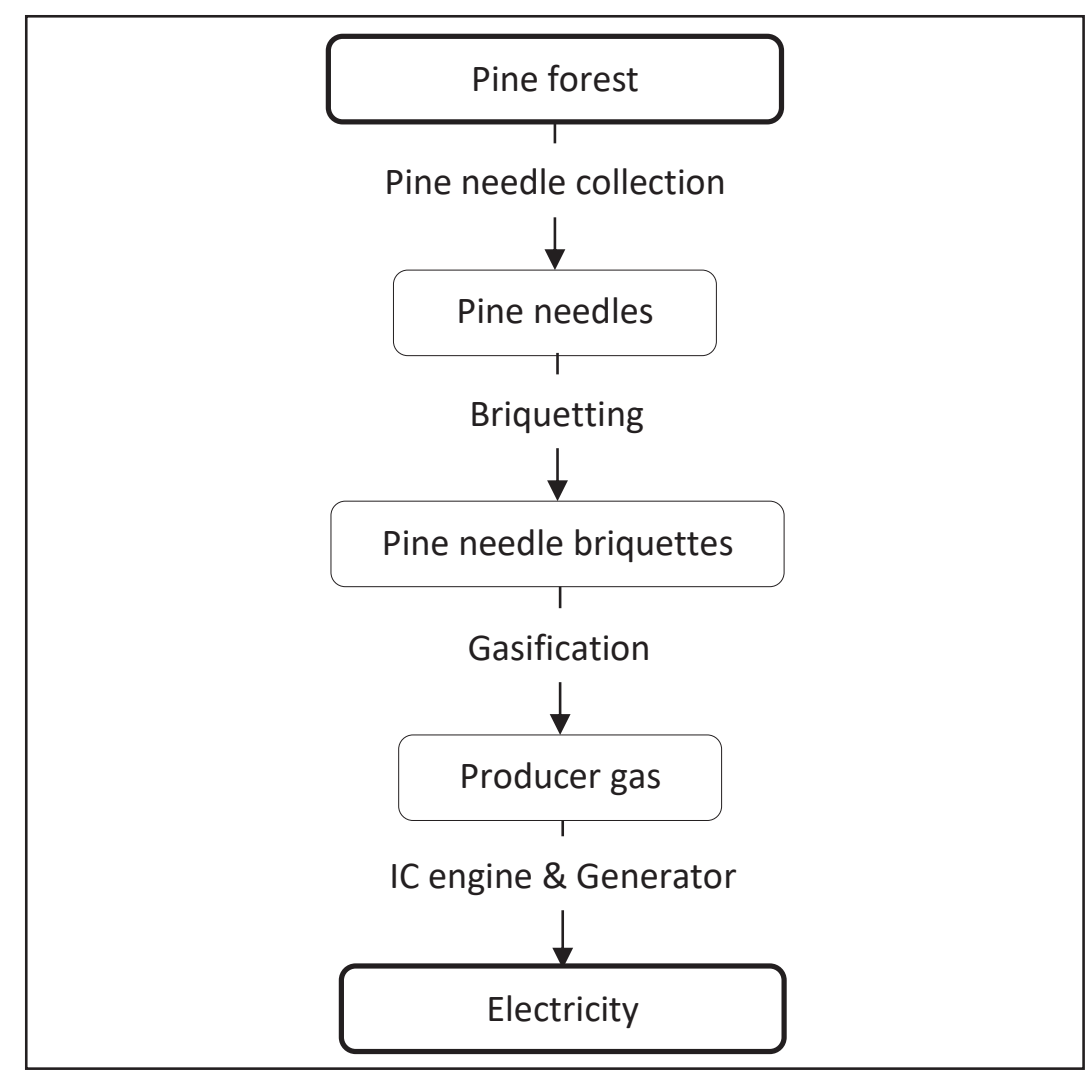

Figure-1: Flow Chart depicting process of power generation from pine needles

Such large scale usage of pine needles need enabling environment in terms of policy thrust and availability of credible associated information such as matrix of pine 
needle availability with particulars of pine forests including yield, location, area, accessibility, proximity to road, etc. This study is an attempt towards evolving such information to promote usage of pine needles as energy feedstock in the state of Uttarakhand. The factors affecting net annual pine needle yield as energy feedstock have been thoroughly discussed, analysed and quantified. Estimates of potential net pine needles available as energy feedstock has been made. The extent of thermal and electrical energy generation using pine needles have also been estimated.

\section{Methodology for estimation of pine needle availability for use as Energy Feedstock}

The estimation of pine needle availability in Uttarakhand as energy feedstock involves assessment of (i) gross annual pine needle yield (ii) pine needles lost as energy feedstock due to various losses, alternative uses, limitations etc., and (iii) net annual pine needle yield as energy feedstock, obtained as the difference of the gross pine needle yield and the amount of pine needles lost.

Tree density based approach is used to estimate pine needle availability potential.The estimation of gross pine needle yield required data on forest cover, forest class or type, tree canopy density, tree canopy cover, tree density, pine needle yield per tree, etc. Two types of forests - very dense forests (VDF) and moderately dense forests (MDF) - are included for the estimation. The forest types along with their classification is given in Section 2.1. Forests with pine trees alone (pure pine forests) are considered for the estimations here as the aim was to obtain first approximation of the pine needle yields. Pine trees however, are also present in mixed pine forests such as pine-sal, pine-oak, etc., which are ignored for this study. It can therefore be argued that these estimates are conservative in nature.

\section{Forest classification}

Forest statistics are generated using satellite based remote sensing technology. This technique classifies forests on the basis of tree canopy density, which is percent land area covered by the overall tree canopy as viewed from top (by the satellite). Forest Survey of India (FSI) has used digital data of LISS-III satellite with spatial resolution of 23.5 metre for India State of Forest Report (ISFR) 2013 [17]. 
Table-2 presents forest classification and related tree canopy density. The forests are classified as very dense forest (VDF), moderately dense forest (MDF), open forest $(\mathrm{OF})$ and scrub forests. For very dense forest tree canopy density is 70 percent and above while for open forest it lies between 10 and 40 percent.

The state of Uttarakhand has total forest cover of 3,799,900 hectares (ha) and this includes reserve forests, protected forests, civil soyam, private forests and special forests [18]. Tree canopy based forest distribution is available for 2,449,200 hectares of reserved forest land. For altitude between 500 - 3000 metres, where pine mainly grows, VDF consists of 413,700 hectares (21 percent), MDF consists of 1,106,900 hectares (56 percent) and OF consists of 455,100 hectares (23 percent) [17].

The area of pine forests in the state is 394,383 hectares (Data for 2011). The class distribution of pine forest is assumed to be same as for the total forest, as such distribution for pine forests is not available.

Table-2: Tree canopy density based categorization of Forests [17]

\begin{tabular}{|l|l|l|}
\hline $\begin{array}{c}\text { S. } \\
\text { No. }\end{array}$ & \multicolumn{1}{|c|}{ Forest class or type } & \multicolumn{1}{c|}{ Tree canopy density } \\
\hline 1 & Very dense forest (VDF) & Canopy density of $70 \%$ and above. \\
\hline 2 & Moderately dense forest (MDF) & Canopy density of $40 \%$ and more but below $70 \%$. \\
\hline 3 & Open forest (OF) & Canopy density of $10 \%$ and more but below $40 \%$. \\
\hline 4 & Scrub & Tree canopy density less than $10 \%$. \\
\hline
\end{tabular}

\section{Estimating gross annual pine needle yield in the state of Uttarakhand}

The pine needle yield of a pine forest may depend upon factors like type of forest, location, etc. All these factors are assumed to be encompassed in the tree canopy density of the forest. For estimation of gross annual pine needle availability, OF may not justify economic pine needle collection owing to small pine needle quantity per unit area. The area under VDF and MDF forests arrived on the basis of the above discussion are given below. 
Area of pine forest, $A_{p f}=394383$ ha

Area of very dense pine forest, $A_{v d f}=82821$ ha

Area of moderately dense pine forest, $\mathrm{A}_{\mathrm{mdf}}=220855 \mathrm{ha}$

Tree canopy density of a forest can be a used to calculate tree density of that forest. Tree canopy density is canopy cover (the sum of tree canopy cover) per unit forest area as seen from top [19]. Tree canopy cover is the area covered by canopy of an individual tree which may nearly be same for each tree in a grown up forest. A VDF forest therefore has more tree canopy density for greater number of trees and MDF has lower tree canopy density and lower number of trees as evident from Table-2. Annual pine needle yield of the forest per unit area can be estimated if along with tree density, per tree pine needle yield is available. Canopy cover of a unit area forest is estimated by $\mathrm{Wu}[20]$. Therefore these parameters can be given as:

(1) Canopy cover $=\frac{\pi}{4} \sum_{i=1}^{n} d i^{2}$

(2) Tree canopy density $=\left[\frac{\pi}{4} \sum_{i=1}^{n} d i^{2}\right] /[$ Forest Area $]$

where $d i$ is the average effective diameter of the tree crown as seen from top.

The effective diameter is smaller than the real diameter of the tree canopy and it may vary as per the tree packing in the forest or the tree density. Closer tree packing may have smaller effective diameter. Gill etal. [19] have reported minimum crown radius as $2.2 \mathrm{~m}$ for conifers. The number of trees obtained for a hectare VDF pine forest is 680 and for MDF forest, 440 per hectare for effective canopy diameter as 4 metre.

Pine needle yield per tree reported in literature varies widely as given in Table-3. The variation may be due to factors such as location, age of trees, method of measurement, etc. These measurement most probably may have been made for the pine forests falling in VDF and MDF forests. The average value therefore has been taken for further estimation.

Table-3: Reported estimates of pine needle yield per tree per year in Uttarakhand 


\begin{tabular}{|c|c|c|c|c|c|}
\hline S. No. & $\begin{array}{c}\text { Source } \\
\text { reference }\end{array}$ & $\begin{array}{c}\text { Needle yield } \\
\mathbf{( k g / h a / y r )}\end{array}$ & $\begin{array}{c}\text { Pine } \\
\text { tree per } \\
\text { ha }\end{array}$ & $\begin{array}{c}\text { Needle yield } \\
\text { per tree (kg/yr) }\end{array}$ & Remarks \\
\hline 1 & {$[21]$} & 5994 & 575 & 9.2 & - \\
\hline 2 & {$[22]$} & 5371 & 278 & 19 & - \\
\hline 3 & {$[22]$} & 5700 & 1630 & 3.5 & Tree density high. \\
\hline 4 & {$[22]$} & 6800 & 657 & 10.4 & - \\
\hline 5 & {$[22]$} & 7400 & 820 & 9 & - \\
\hline 6 & {$[22]$} & 7600 & 540 & 14.1 & - \\
\hline 7 & {$[23]$} & 8900 & 700 & 12.7 & - \\
\hline
\end{tabular}

Annual Pine Needle Yield (APNY) for the state now can be obtained as following.

APNY $=\left(\mathrm{A}_{\mathrm{vdf}}\right) \times\left(\mathrm{N}_{\text {tree, }}\right.$ df $) \times\left(\mathrm{PNY}_{\text {tree }}\right)+\left(\mathrm{A}_{\mathrm{mdf}}\right) \times\left(\mathrm{N}_{\text {tree, } \mathrm{mdf}}\right) \times\left(\mathrm{PNY}_{\text {tree }}\right)$

where $\mathrm{N}$ refers to number of pine trees per hectare, PNY indicates pine needle yield per year and others refer to their usual representation.

\section{Estimation of pine needles available for use as energy feedstock}

The methodology developed above will give the gross annual pine needle yield. This amount may not be entirely available as energy feedstock because of pine needles lost due to reasons ranging from physical access to cultural behaviour. These losses may be due to poor accessibility, alternative traditional uses of pine needles, forest fires and various losses such as due to rains, winds, storage, transportation, etc. These are analysed in the following paragraphs. 
Pine needles for use as energy feedstock would entail collection from the forests and taken to the site of the gasifier power generation unit. Pine forests exist from the height of 500 metres to 3500 metres and physical accessibility being an issue at several locations may impact collection of pine needles. Accessibility of pine forests may be affected due to steep slopes, gorges, difficult terrains, etc., making it humanly difficult to collect pine needles. Forests at higher reaches, say above 3000 metre height, may pose greater difficulty and 8 percent of forest lies above this height [17].

Accessibility also means distance from inhabitation where it is economically not feasible to collect pine needles. This includes isolated patches of forests. Presence of wild dangerous animals may also hamper accessibility. Forests have thorny shrubs and other undercover vegetation that makes traversing for pine needle collection difficult. An estimated 20 percent of pine forest may be difficult due to accessibility related reasons causing loss in pine needle collection for energy feedstock.

Pine needles do find some use in villages close to pine forests. This mostly pertains to livestock bedding material [24]. Other uses are small and can be ignored. Cattle population in hills of Uttarakhand is estimated to be 2.43 million [25]. About 15 percent of families in the hills of the state are expected to be using pine needles for animal bedding. An animal may be needing about $1.5 \mathrm{~kg}$ of pine needle as bedding material per night. The total annual usage of pine needles for animal bedding may be about 24337 tons.

No alternate use of pine needles other than animal bedding is reported. Attempts are being made to make use of pine needles using new technologies for paper making, chemical extraction, as fuel in cookstoves, etc., but such efforts will take some time before their wide scale acceptability. These therefore have no impact on current estimates.

Forest fires also render loss of pine needles. Forest fire data for last 15 years reveal that the forest area affected by forest fire has been between a low of 231 hectares to a high of 4983 hectares [18]. On an average 4000 hectares can be taken as the forest 
area affected by fire and loss of its pine needle yield. This is about 1 percent of the total pine forest area in Uttarakhand.

Loss of pine needles may occur due to winds and rains. Excessive wind may blow pine needles to inaccessible surface and rains strong water current may wash pine needles lying in the stream path. The loss due to both these can be minimised by periodic pine needle collection. Pine needle availability may also be affected by reasons owing to inefficient collection.

Pine needles have low bulk density require large space for storage. The storage is inevitable for ensuring constant availability of pine needles for their utilisation. The storage is best located at the site of utilisation of pine needles and necessitates transportation from pine forests. Losses in storage and transportation are also likely to occur. Together, all these losses may be taken as about 10 percent.

The discussion above yields values of loss factor affecting pine needle availability as energy feedstock in Uttarakhand. These factors enable estimation of the shortfall in net pine needle collection as energy feedstock. Table- 4 gives a summary of these in terms of loss factors.

Table-4: Loss factors for estimating annual pine needle yield

\begin{tabular}{|l|l|c|l|}
\hline S. No. & Loss factor type & Value & \multicolumn{1}{|c|}{ Reasons } \\
\hline 1 & Accessibility & 0.2 & $\begin{array}{l}\text { Difficult terrain, distance, undercover } \\
\text { deterrence }\end{array}$ \\
\hline 2 & Alternative uses & 0.01 & Mainly animal bedding \\
\hline 3 & Forest fire & 0.01 & Burnt by forest fire \\
\hline 4 & $\begin{array}{l}\text { Various other } \\
\text { losses }\end{array}$ & 0.1 & $\begin{array}{l}\text { Washed away by rains, blown by } \\
\text { winds, transportation and storage loss }\end{array}$ \\
\hline & Total & $\begin{array}{c}\mathbf{0 . 3 2} \text { say } \\
\mathbf{0 . 3}\end{array}$ & \\
\hline
\end{tabular}


Loss due to accessibility, estimated at 20 percent, carries highest significance in estimation of pine needle lost as energy feedstock. About 10 percent loss of pine needles occur on account of various other losses together such as loss due to rains, winds, during transportation and storage. Alternative uses and forest fire account for loss of pine needles at 1 percent each. The net loss factor can be taken as 0.3 . This leaves 70 percent of annual gross pine needle yield available for use as energy feedstock and can be called net annual pine needle yield for the state.

\section{Primary and net energy from pine needles}

Primary Energy available annually is the energy available in pine needles for conversion into other energy forms. Estimation of Net Energy has been carried out in terms of electric energy and thermal energy. For electric energy, producer gas generated in a gasifier can operate a modified IC engine coupled with an electric generator [7,26,27]. Producer gas is a fuel gas containing $\mathrm{CO}, \mathrm{H}_{2}, \mathrm{CH}_{4}, \mathrm{CO}_{2}$ and $\mathrm{N}_{2}$ gases. The conversion is generally possible at an efficiency of 0.2 [28]. The installed capacity for electricity generation will depend upon daily generation hours decided by the application of electricity. The energy in pine needles can be used for process heating and its estimation has also been carried out. In industrial sector, boiler is employed for process heating applications. Boiler efficiency of $66 \%$ have been reported for biomass boiler by Chau etal. [29].

\section{Results and Discussion}

The estimation of gross annual pine needle yield has been carried out. Losses in pine needle as energy feedstock based on loss factors are also estimated. Using these figures, net annual pine needle yield is estimated. Table-5 presents a summary of the input parameters for these estimations.

Table-5: Input parameters for gross annual pine needle yield estimation

\begin{tabular}{|c|c|c|c|}
\hline $\begin{array}{c}\text { S.N } \\
\text { o. }\end{array}$ & Parameter & Units & Value \\
\hline
\end{tabular}




\begin{tabular}{|l|l|c|c|}
\hline 1 & Area pine forest, $\mathrm{A}_{\mathrm{pf}}$ & ha & 394383 \\
\hline 2 & Area very dense forest, $\mathrm{A}_{\mathrm{vdf}}$ & ha & 82821 \\
\hline 3 & $\begin{array}{l}\text { Area moderately dense forest, } \\
\mathrm{A}_{\mathrm{mdf}}\end{array}$ & ha & 220855 \\
\hline 4 & Number of tree VDF, $\mathrm{N}_{\text {tree,vdf }}$ & No. & 680 \\
\hline 5 & Number of tree MDF, $\mathrm{N}_{\text {tree,mdf }}$ & No. & 440 \\
\hline 6 & Pine needle yield per tree, $\mathrm{PNY}$ tree & $\mathrm{kg} /$ tree & 12.4 \\
\hline
\end{tabular}

The results of gross annual pine needle yield (APNY) and the net annual pine needle yield (NAPNY) for the state of Uttarakhand are given in Table-6. The estimated value of gross annual pine needle yield is 1.90 million tonnes. The net annual pine needle yield is 1.33 million tonnes.

Table- 6 also gives results obtained for potential annual primary energy (APE) and annual net energy (ANE) when pine needles are used as energy feedstock. The annual primary energy obtained from pine needles is 25.9 peta joules (PJ). The annual net energy for thermal applications is estimated at 17.1 PJ. For electricity generation, annual net energy (ANE) potential using pine needles is 1438.9 million $\mathrm{kWh}$. This estimation is based on electricity generation through gasification route using gasifier-engine-generator combination.

Table-6: Pine needle gross and net yields and energy potential

\begin{tabular}{|c|c|c|c|}
\hline $\begin{array}{c}\text { S.N } \\
\text { o. }\end{array}$ & Parameter & Unit & Value \\
\hline & Pine needles & & \\
\hline 1 & $\begin{array}{l}\text { Gross annual pine needle } \\
\text { yield }\end{array}$ & $\begin{array}{l}\text { million } \\
\text { tons }\end{array}$ & 1.90 \\
\hline 2 & $\begin{array}{l}\text { Net annual pine needle } \\
\text { yield }\end{array}$ & $\begin{array}{l}\text { million } \\
\text { tons }\end{array}$ & 1.33 \\
\hline & Energy potential & & \\
\hline
\end{tabular}




\begin{tabular}{|l|l|l|l|}
\hline 3 & Annual primary energy & $\begin{array}{l}\text { peta } \\
\text { joules }\end{array}$ & 25.90 \\
\hline 4 & $\begin{array}{l}\text { Annual net energy } \\
\text { (Thermal) }\end{array}$ & $\begin{array}{l}\text { peta } \\
\text { joules }\end{array}$ & 17.10 \\
\hline 5 & $\begin{array}{l}\text { Annual net energy } \\
\text { (Electrical) }\end{array}$ & $\begin{array}{l}\text { million } \\
\mathrm{kWh}\end{array}$ & 1438.90 \\
\hline
\end{tabular}

The annual net energy (ANE) potenial of pine needles may be seen in the background of electricity consumption for the state. For the commercial sector alone, state's consumption of electricity was 1411 million $\mathrm{kWh}$ in the year 2013-14 [3]. For realising the net annual energy potential of pine needles as given in Table-6, installed capacities of the generation units have been estimated. Table- 7 gives cumulative generation capacity for two different user specific scenarios. In the event of supplying power for 5 hours a day, say for rural households in the vicinity of pine needle based generation units, 789 MW intalled capacity is needed. Whereas for round the clock electricity generation, an installed capacity of $165 \mathrm{MW}$ is required.

Table-7: Cumulative installed capacity of pine needle power generation units

\begin{tabular}{|l|l|c|}
\hline $\begin{array}{c}\text { S.No } \\
\cdot\end{array}$ & \multicolumn{1}{|c|}{ Generation hours } & $\begin{array}{c}\text { Cumulative } \\
\text { installed capacity } \\
\text { (MW) }\end{array}$ \\
\hline 1 & $\begin{array}{l}\text { Five hours per day electricity for rural } \\
\text { households }\end{array}$ & 789 \\
\hline 2 & Round the clock generation & 165 \\
\hline
\end{tabular}

\section{Concluding Remarks}

The central Himalayan state of Uttarakhand in India generates large amount of pine needles on forest floors. Estimation of pine needles produced has been made. The 
gross annual pine needle yield in the state obtained using tree canopy density method has been estimated at 1.9 million tonnes. Net annual pine needle yield as energy feedstock is affected by factors such as accessibility, alternative uses, rains and winds, various other losses, etc. The discussion and subsequent estimation here puts these losses at nearly 30 percent. The net annual pine needle yield is estimated at 1.33 million tonnes. The annual pimary energy potential of pine needles in the state have been estaimated at 25.9 peta joules. The annual net energy is estimated at 17.1 PJ for thermal applications. Alternatively, an estimated amount of 1438.9 million $\mathrm{kWh}$ of electrical energy can be obtained. This is a significant amount as commercial sector in Uttarakhand consumed 1411 million kWh in the year 2013-14.

\section{References:}

[1] Daily System Energy Report. Uttarakhand Power Corporation Limited (UPCL), Government of Uttarakhand, Dehradun; 2015. Website: https://www.upcl.org/wss/ViewDailySupplyPos.htm [Accessed 20.01.2015].

[2] Uttarakhand 24x7 Power for All (UPFA). A Joint Initiative of Government of India and Government of Uttarakhand, India; 2015.

[3] Statistical Diary Uttarakhand. Directorate of Economics and Statistics Uttarakhand (DESU), Dehradun, India; 2015.

[4] Chauhan A, and Saini RP. Renewable energy based off-grid rural electrification in Uttarakhand state of India: Technology options, modelling method, barriers and recommendations. Renewable and Sustainable Energy Reviews 2015; 51: 662-681.

[5] Chauhan S, and Silori CS. Assessment of biomass availability for power Generation in selected talukas of Uttranchal state. ENVIS Bulletin: Himalayan Ecology 2004; 12(2).

[6] McKendry P. Energy production from biomass (part 2): Conversion technologies. Bioresource Technology 2002; 83(1): 47-54. http://doi.org/10.1016/S09608524(01)00119-5

[7] Martinez JD, Mahkamov K, Andrade RV, and Silva Lora EE. Syngas production in downdraft biomass gasifiers and its application using internal combustion engines. Renewable Energy 2012; 38(1): 1-9. 
[8] Erlich C, and Fransson TH. Downdraft gasification of pellets made of wood, palm-oil residues respective bagasse: Experimental study. Applied Energy 2011; 88: 899-908.

[9] Kala LD, Susastriawan AAP, Subbarao PMV, and Subrahmanyam JP. Performance investigations on gasification of pongamia shells in a conventional downdraft gasifier, In: Proceedings of International Symposium on Aspects of Mechanical Engineering and Technology for Industry (AMETI); 2014.

[10] FAO. Wood Fuels Handbook. Food and Agriculture Organisation of United Nations; 2015.

[11] Dhaundiyal A, and Gupta VK. The Analysis of Pine Needles as a Substrate for Gasification. Hydro Nepal 2014; 15: 73 - 81.

[12] Sharma A. Assessing the Suitability of Various Feedstocks for Biomass Gasification. M.Sc. Thesis, Dept. of Biological \& Ag. Engg., Luisiana State University; 2006.

[13] Mansaray KG, amd Ghaly AE. Physical and thermochemical properties of rice husk. Energy Sources 2007; 19(9): 989-1004, DOI: 10.1080/00908319708908904.

[14] Clarke S, and Preto F. Biomass densification for energy production. Ministry of Agriculture Food and Rural Affairs, Govt. of Canada; 2011.

[15] Dahal M, Baral B, Karki S, Dahal S, and Banjara R. Pine needle briquette as a promising fuel for gasifier. In: Rentech Symposium Compendium 2014; Vol. 4: pp 31 - 34.

[16] Jain VK, and Srinivas SN (Eds). Empowering Rural India the RE Way. Ministry of New and Renewable Energy, Government of India, New Delhi, India; 2012

[17] India State of Forest Report (ISFR 2013). Forest Survey of India, Dehradun; 2013.

[18] Uttarakhand Forest Statistics (UFS). Uttarakhand Forest Department, Dehradun, India; 2013.

[19] Gill Samantha J, Biging GS, and Murphy EC. Modeling conifer tree crown radius and estimating canopy cover. Forest Ecology and Management 2000; 126(3): 405-416.

[20] Wu W. Derivation of tree canopy cover by multiscale remote sensing approach. ISPRS Workshop on Geospatial Data Infrastructure: from data acquisition and updating to smarter services; 2011.

[21] Rana BS, Singh SP, and Singh RP. Biomass and net primary productivity in central Himalayan forests along an altitudinal gradient. Forest Ecology and Management 1989; 27: 199-218.

[22] Kaul ON, Negi JDS, Sharma DC and Srivastava PBL. Organic matter and plant nutrient distribution in a chir (Pinus roxburgii) plantation. Indian For. 1981; 107(2): 86-95.

[23] Singh SP, Adhikari BS, and Zobel DB. Biomass, Productivity, Leaf Longevity, and Forest Structure in the Central Himalaya. Ecological Monographs 1994; 64(4): 401-421. 
[24] Kala CP. Indigenous uses and structure of chir pine forest in Uttaranchal Himalaya, India. International Journal of Sustainable Development \& World Ecology 2004; 11(2): 205210. <DOI: 10.1080/13504500409469824>

[25] Uttarakhand at a Glance. Directorate of Economics and Statistics Uttarakhand (DESU), Dehradun, India; 2015b.

[26] Reed TB, and Das A. Handbook of Biomass Downdraft Gasifier Engine Systems, Solar Energy Research Institute (SERI), Colorado; 1988.

[27] Basu Prabir. Biomass Gasification and Pyrolysis: Practical Design and Theory, Academic Press Elsevier, USA; 2010.

[28] McKendry P. Energy production from biomass (part 1): overview of biomass. Bioresource Technology 2002; 83(1): 37-46.

[29] Chau J, Sowlati T, Sokhansanj S, Preto F, Melin S, and Bi X. Techno-economic analysis of wood biomass boilers for the greenhouse industry. Applied Energy 2009; 86: 364-371. 